\title{
Council for Medical Schemes braves the tightrope between funders and the poor
}

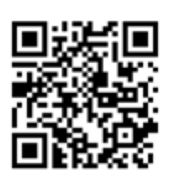

A new regulatory framework will in January 2016 enable medical schemes to offer low-cost, limited-benefit primary care medical aid, expanding private healthcare coverage by an extra 12.7 million people (from the current decade-long-stagnant 8.7 million higher-income members).

It's being touted as a potential trigger for private health access reform, complementing the impending National Health Insurance aimed at more equitable healthcare access for the other $84 \%$ of the population, most of whom depend on the overloaded, often dysfunctional public sector. Paresh Prema, Head of Benefit Management at the Council for Medical Schemes (CMS) and Johan Pretorius, CEO of Universal Health, told the Board of Healthcare Funders annual conference in Cape Town this July that the key to keeping low-income benefit option costs down lay in having healthcare provider networks that charged agreed-upon rates. Pretorius proposed to the CMS guideline architects that scheme members so covered should fall below the tax threshold (R5 296 per month). The CMS is considering restricting membership of the lowcost options to people with an income below R6 000 a month (but possibly up to R12 000), or prohibiting members from moving from more expensive options to the new low-cost options and/or limiting membership to those who have not been a member of a scheme before. The hope is also that not offering full private hospital cover will deter some members of more expensive options from moving to them or 'buying down'. The Council is also reviewing a proposal to exempt the new options from having to hold reserves equal to $25 \%$ of contributions. Pretorius said administrators of medical schemes had proved that it cost more to provide membership to individuals than to groups.

\footnotetext{
Marrying cost-efficiency with decent benefits

At its August 2015 sitting, the CMS approved the exemption framework and principles allowing for the introduction and registration of low-cost benefit options in the medical schemes industry effective from 1 January 2016 - in an attempt to marry cost efficiency with decent benefits. Prema said that the guidelines for exemption from the Act were drawn up after consultation with
}

two scheme administrators, two medical aid schemes and some specialist provider groups and would be published soon after approval by the CMS's 13-member governing board. This should enable schemes to get their low-income options in place by January next year. However, individual schemes would first have to make their submissions to the CMS for approval based on the exemption guidelines. Delays might occur, because most schemes would simultaneously be planning their overall benefits for next year.

Each of the 12 guideline submissions from the industry had laid out the costs of two primary care options. The most basic offered three GP visits, basic dentistry and optometry, and basic pathology and radiology services - but no emergency or private hospital care. The benefits were based on feedback from households surveyed a decade ago in research commissioned by the CMS. Sacrificed on the altar of cost-efficiency are prescribed minimum benefits (PMBs), an extensive set of medical conditions, chronic diseases and emergency care that the Medical Schemes Act says must otherwise be provided by all medical schemes.

\section{Prema said the guidelines for exception from the Act were drawn up after consultation with two scheme administrators, two medical aid schemes and some specialist provider groups and would be published soon after approval by the CMS's 13-member governing board.}

\section{Costs of $\mathrm{PMBs}$ rising}

Pretorius said it cost schemes R508 per person per month to provide cover for PMB benefits in 2013, a figure he estimates has risen to about R600 per month.

Prema said of the guidelines his team have drawn up: 'It will motivate the exceptional case for all schemes. It's around affordability. We want to simplify it so that schemes know what is expected when they apply - and it's entirely around primary healthcare products', he explained. One idea was to see if it was costeffective to have higher minimum benefits: 'We don't want it to be too onerous to [prevent it] reach[ing] the target market.' The original lower-income medical schemes survey was done in 2005 , so subsequent salary hikes and

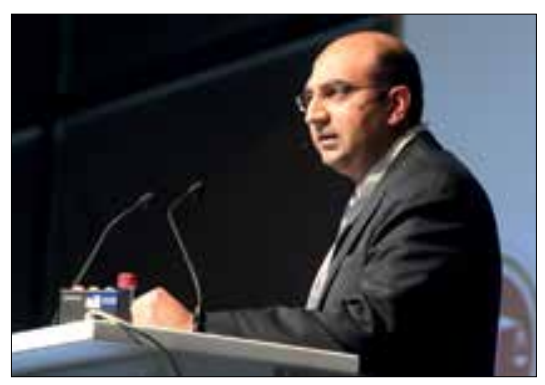

Paresh Prema, Head of Benefit Management at the Council for Medical Schemes.

inflation needed to be taken into account to avoid running the risk of prescribing a minimum benefit not valued by the market. 'We're hoping that specialties like radiology and pathology will buy into it and provide benefits at a lower cost, because they realise that this is aimed at a lower-income market. It'll take time for everybody to buy into - that's why the exemption process is a good start.' $\mathrm{He}$ said that the generic benefit package being proposed was 'more about what the benefits are and not what diseases are covered.' 'We have to change the way in which we sell or structure this product to deal with what benefits will be used. It doesn't make sense to have a PMB package covering 270 conditions at a cost that is unaffordable - and not dealing with the immediate needs'. Asked to elaborate on the 'package', he said it would deal with the day-to-day immediate needs of members such as consultations and acute and chronic medications. 'It's what people in the market are willing to pay for to avoid a [public sector] queue or miss a day's work.' The idea was to help schemes grow their memberships and increase access to healthcare.

Only about one million medical scheme members $(10.87 \%$ of total lives covered) currently belong to low-cost options that offer benefits via provider networks. Pretorius called on providers to offer more low-cost services that could be included in the new options, suggesting that the Council might consider allowing schemes to restrict membership of the low-cost options to people who live in areas where there were provider networks to service them.

\section{Chris Bateman}

chrisb@hmpg.co.za

$S$ Afr Med J 2015;105(11):889.

DOI:10.7196/SAMJ.2015.v105i11.10199 